\title{
Adsorção de molibdato em minerais de argilas naturais e modificadas com ácido sulfúrico, ácido húmico e uréia
}

\section{(Adsorption of $\mathrm{MoO}_{4}^{2-}$ in clay natural minerals and modified with sulfuric acid, humic acid and urea)}

\author{
P. M. Pereira', V. P. Lemos ${ }^{1}$, E. Rodrigues ${ }^{2}$, K. C. F. Faial ${ }^{3}$ \\ ${ }^{1}$ Instituto de Geociências, Universidade Federal do Pará, Rua augusto Corrêa s/n, Belém, PA 66093-110 \\ ${ }^{2}$ Faculdade de Química, Universidade Federal do Pará \\ ${ }^{3}$ Instituto Evandro Chagas, BR 316, Km 07- Levilândia, Belém, PA 67000-030 \\ lpatricia_magalhaes@ymail.com
}

\begin{abstract}
Resumo
Sedimentos argilosos provenientes do município Assis Brasil, Acre, foram lixiviados com soluções de ácido sulfúrico, ácido húmico e uréia, visando avaliar a capacidade de retenção de molibdato nesses materiais e investigar a viabilidade do processo de adsorção na interface sólido-solução. Os materiais foram caracterizados a partir de dados de difração de raios X, espectros FTIR, cargas superficiais e composição química. Os modelos de isotermas de Langmuir, Freundlich e Sips foram usados no ajuste dos dados experimentais de adsorção. Os minerais identificados nos sedimentos argilosos foram esmectita, caulinita, ilita, quartzo, albita, microclineo e calcita. A modificação química promoveu a amorfização da amostra modificada com ácido sulfúrico e delaminação ao longo do plano 001 da amostra modificada com uréia. Os ajustes matemáticos definidos pelos parâmetros $\left(\mathrm{K}_{\mathrm{L}}, \mathrm{K}_{\mathrm{f}}\right)$ das isotermas de adsorção, avaliação de $\mathrm{C}_{\mathrm{e}} v s . \mathrm{q}_{\mathrm{e}}, \mathrm{pH}$ vs. $\mathrm{q}_{\mathrm{e}}$, Qmáx (sips) e Kd indicaram que a amostra $\mathrm{S} 10 \mathrm{H} 15$ é a mais eficiente na adsorção de $\mathrm{MoO}_{4}^{2-}$, com q $\mathrm{máx}=6,83 \mathrm{mg} \cdot \mathrm{L}^{-1}$.
\end{abstract}

Palavras-chave: adsorção, molibdato, minerais.

\begin{abstract}
Clay sediments from the municipalities Assis Brazil (Acre), were leached with solutions of sulfuric acid, humic acid and urea, to evaluate the retention capacity of molybdate in these materials and to investigate the feasibility of the adsorption processes at solidsolution interfaces. The materials were characterized from data of XRD, FTIR spectra, surface charge and chemical composition. The Langmuir isotherm models, Freundlich and Sips were used to fit the experimental data of adsorption. The minerals identified in the clay sediments were smectite, kaolinite, illite, quartz, albite, calcite and microclineo. The chemical modification leads amorphization of the modified sample with sulfuric acid and delamination along the plane 001 of the modified sample with urea. The settings defined by mathematical parameters $\left(K_{L}, K\right)$ of the adsorption isotherms, evaluation $C_{e} v s . q_{e^{\prime}} p H v s . q_{e^{\prime}} Q_{\text {max }}$ (sips) and $\mathrm{Kd}$, indicated that the $\mathrm{S} 10 \mathrm{H} 15$ sample is more efficient in the adsorption $\mathrm{MoO}_{4}^{2-}$, with com $q_{\max }=6.83 \mathrm{mg} . \mathrm{L}^{-1}$.
\end{abstract}

Keywords:adsorption, molibdate, minerals.

\section{INTRODUÇÃO}

A busca por metodologias eficientes no controle da poluição ambiental, assim como o desenvolvimento de tecnologias nos âmbitos químico, físico e biológico têm sido amplamente discutida a fim produzir alternativas eficientes na melhoria da qualidade de vida e controle de poluentes químicos (orgânicos ou inorgânicos), que ao longo dos anos estão sendo descartados no meio ambiente sem tratamento adequado por residências e indústrias.

Metais pesados altamente reativos e bioacumuláveis provenientes da atividade mineradora, industrial e agrícola, tais como $\mathrm{Mn}, \mathrm{Pb}, \mathrm{Cd}, \mathrm{Hg}, \mathrm{Cr}$ e $\mathrm{Mo}$, representam um sério problema ambiental, pois dependendo da espécie química presente, são altamente tóxicos ao ser humano e contaminam o ambiente (aquático ou terrestre), acarretando interferência destrutiva à flora, fauna e impossibilitando seu uso para fins humano. O molibdênio constituinte do grupo do crômio apresenta configuração eletrônica no estado fundamental $\mathrm{d}^{5} \mathrm{~s}^{1}$, possui estados de oxidação $2+, 3+, 4+, 5+$ e $6+$, sendo mais estáveis os estados $4+$ e $6+$, possui concentração média na crosta terrestre em torno de $1,5 \mathrm{mg} / \mathrm{kg}$ [1], considerável toxicidade, estando seu grau de toxicidade entre os dos compostos $\mathrm{Zn}^{2+}$ e $\mathrm{Cr}^{3+}$ [2]. Este elemento pode ser encontrado em minerais na forma de molibdenita $\left(\mathrm{MoS}_{2}\right)$, powellita $\left(\mathrm{Ca}(\mathrm{MoW}) \mathrm{O}_{4}\right)$, molibdita $\left(\mathrm{Fe}_{2} \mathrm{O}_{3} \cdot 3 \mathrm{MoO}_{3} .8 \mathrm{H}_{2} \mathrm{O}\right)$ e wulfenita $\left(\mathrm{PbMoO}_{4}\right)$, podendo ser obtida também como subproduto de minérios de cobre e quando em presença de ar convertido a $\mathrm{MoS}_{3}$ [3]. Elevadas concentrações do íon molibdato $\left(0,5-20 \mathrm{mg} . \mathrm{L}^{-1}\right)$ podem ser encontrados nas indústrias agrícolas e de mineração onde há grandes volumes de efluentes, gerados pela lixiviação e 
flotação indesejada de molibdenita. São inúmeros os estudos de adsorção visando à retenção de metais poluentes, mas pouco tem sido investigado a respeito da adsorção de molibdênio. No solo o molibdênio é encontrado principalmente como ânion molibdato $\left(\mathrm{MoO}_{4}^{2-}\right)$, mas também como ácido molíbdico $\left(\mathrm{H}_{2} \mathrm{MoO}_{4}\right)$. Apesar de o molibdênio ser um elemento essencial em processos biológicos de plantas e animais, pode vir a ser um elemento tóxico que em elevadas concentrações (limite aceitável: nos solos 24 ppm, em água de 0,06 e 1,10 mg/L) [4] são extremamente nocivas ao homem e meio ambiente. A aplicação do molibdênio nos processos industriais, atuando em substituição ao chumbo e cromo em pigmentos de tintas anticorrosivas, assim como em aplicações específicas na área de catálise, tem sido objeto de estudos, além de ser um elemento essencial em determinadas funções biológicas de plantas e animais. $\mathrm{O}$ aumento na demanda na indústria de aço, fertilizantes, agrícola, mineração e nas mais diversas aplicações tem gerado disfunções patológicas nos seres humanos ocasionando problemas de saúde irreversíveis. Teores elevados de Mo no organismo humano pode causar disfunções como: deformidade nas articulações, distúrbios neurológicos, vômitos, diarréia, anemia, diminuição na taxa de crescimento, síndrome da gota [5, 6]. O molibdênio possui forte tendência a acumular-se em solo ricos em matéria orgânica, em geral pode ser adsorvido por argilas. As argilas naturais ou modificadas podem ser aplicadas em processos industriais como precursora de adsorventes ou absorventes, em tratamento de águas, adsorção de mercúrio [7], controle de herbicidas, remoção de $\mathrm{Cr}$ (III), $\mathrm{Cr}(\mathrm{VI})$ a partir de soluções e em ambientes aquáticos [79], remoção de compostos fenólicos amplamente utilizados na indústria farmacêutica, petroquímica [10], demonstram a potencialidade destes materiais nas mais diversas aplicações industriais. No entanto, assim como outros metais de transição, o molibdênio e seus compostos são tóxicos, com grau de toxidez comparável ao $\mathrm{Zn}^{2+} \mathrm{e}$ ao $\mathrm{Cr}^{3+}$ [7].

As argilas usadas nos processos industriais e remediação de solos são modificadas tanto com substâncias inorgânicas quanto orgânicas. As modificações promovem aumento da área superficial específica do material, aumento da capacidade de troca catiônica (CTC), ocasionado pela substituição de cátions das camadas tetraédricas e octaédricas e remove impurezas orgânicas e inorgânicas. Em esmectitas pode ocorrer o aumento em $80 \%$ na superfície especifica do material devido à esfoliação e criação de poros no material, assim como, no caso de bentonita a área superficial de $200 \mathrm{a} 400 \mathrm{~m}^{2} / \mathrm{g}$ [11].

A modificação com ácidos inorgânicos, usualmente $\mathrm{HCl} / \mathrm{H}_{2} \mathrm{SO}_{4}$, é um dos métodos eficientes na produção de materiais ativos para aplicações na industria de descoloração de óleos vegetais, catalisadores, adsorventes, entre outros [12-14].

Minerais de argila do grupo da esmectita sob ativação ácida pode promover a substituição dos cátions $\left(\mathrm{Na}^{+}, \mathrm{K}^{+}\right.$ e $\mathrm{Ca}^{2+}$ ) pelo cátion hidroxônio $\left(\mathrm{H}^{+}\right)$, além de reduzir o teor de $\left(\mathrm{Al}^{3+}, \mathrm{Fe}^{3+}, \mathrm{Mg}^{2+}\right)$ com conseqüente delaminação ou destruição das folhas octaédricas. Os cátions presentes nas bordas das folhas octaédricas são expostos, tornandose solúveis, com isto, há aumento no diâmetro dos poros e área específica destes materiais e conseqüente redução referente ao pico $\mathrm{d}_{(001)}$ nos minerais 2:1, isto ocorre devido a possíveis distorções nos arranjos dos íons que constituem a camada octáedrica devido à troca iônica dos cátions por $\mathrm{H}^{+}[15]$.

Substâncias orgânicas como ácido húmico $\left(\mathrm{C}_{187} \mathrm{H}_{186} \mathrm{O}_{85} \mathrm{~N}_{9} \mathrm{~S}\right)$ e a uréia $\left(\left(\mathrm{NH}_{2}\right)_{2} \mathrm{CO}\right)$ podem ser utilizadas nas modificações de minerais de argila. A presença dos grupos funcionais oxigenados em sua composição possibilita a interação destas substâncias com metais em sistemas aquosos devido à formação do complexo metal-ácido húmico. A complexação de íons metálicos é de suma importância para retenção e mobilidade destes contaminantes em solos e água. Os mecanismos de interação entre ácido húmico com os argilominerais não são bem definidos devido à complexa rede estrutural da substância, porém é possível que ocorra interação dos ânions com as bordas do cristal, formação de pontes de hidrogênio na superfície da argila, adsorção nos espaços interlamelares ou ligações fracas do tipo van der Walls entre hidrogênio e os grupos silanol [16, 17]. A interação de moléculas orgânicas neutras no espaço interlamelar deve-se a presença de oxigênio nas superfícies das folhas tetraédricas que podem agir como doadores de prótons e formar ligações de hidrogênio com as moléculas que contenham os grupos (-OH) ou (-NH), como no caso da uréia, o tratamento térmico, as condições de síntese - úmida ou á seco (moagem) são consideradas fatores importantes neste processo $[18,19]$. A inserção da uréia $\left(\left(\mathrm{NH}_{2}\right)_{2} \mathrm{CO}\right)$ nas camadas da esmectita ocorre devido a protonação dos grupos - $\mathrm{NH}$ pela água, seguido da troca do $\mathrm{NH}_{2}$ pelo cátion trocável da estrutura através de ligações de pontes de hidrogênio, esta inserção é interagida por forças íon dipolo devido a doação de um próton do grupo $\mathrm{NH}_{2}$ aos sítios básicos da esmectita [15].

Neste trabalho o principal objetivo foi avaliar a capacidade de adsorção de molibdato em sedimentos argilosos do estado do Acre, sem tratamentos e modificados com $\mathrm{H}_{2} \mathrm{SO}_{4}$ uréia e ácido húmico e investigar a viabilidade do processo de adsorção nas interfaces sólido-soluções.

\section{MATERIAIS E MÉTODOS}

Materiais: as amostras investigadas foram coletadas em pontos distintos da rodovia BR 317, Assis Brasil, Acre, extremo sudoeste da Amazônia brasileira, com coordenadas geográficas em UTM: S2 (5439240 S - 87920830 W); S10 (5445769 S - $8797646 \mathrm{~W})$. Todas as amostras naturais utilizadas neste trabalho foram trituradas, quarteadas e pulverizadas mecanicamente para posterior processo de modificação. As amostras S2 e S10 foram selecionadas por conterem significativo teor de argilomineral (esmectita e caulinita) para modificação inorgânica e orgânica, as simbologias utilizadas referem-se aos pontos de coleta (S2 e S10). 
Tratamentos das amostras (ácido sulfúrico, ácido húmico e uréia): a modificação com ácido sulfúrico foi realizada nas etapas sequenciais [20]: lixiviação de $6 \mathrm{~g}$ com $300 \mathrm{~mL}$ de $\mathrm{H}_{2} \mathrm{SO}_{4}$, em diferentes concentrações $(0,25 ; 0,5 ; 1$ e $1,5 \mathrm{Mol} / \mathrm{L}$ ) sob aquecimento por $2 \mathrm{~h} / 90{ }^{\circ} \mathrm{C}$; resfriamento à temperatura ambiente; filtrações á vácuo e lavagens com $200 \mathrm{~mL}$ de água deionizada com 3 repetições. As amostras permaneceram em repouso por $15 \mathrm{~h}$ e secagem em estufa a $100^{\circ} \mathrm{C} / 10 \mathrm{~h}$. As amostras receberam a denominação segundo as concentrações $(0,25 ; 0,5 ; 1 \mathrm{e} 1,5 \mathrm{Mol} / \mathrm{L})$ utilizadas: $\mathrm{S} 2 \mathrm{H} 25$; S2H5; S2H1; S2H15. S10H25; S10H5; S10H1; S10H15. A modificação com ácido húmico foi efetuado na seqüência [21]: preparação de uma solução estoque contendo $100 \mathrm{~mL}$ de água deionizada, $10 \mathrm{~mL}$ de $\mathrm{NaOH}$ e $0,1 \mathrm{~g}$ ácido húmico, $\mathrm{pH}=9$; tratamento de $2,5 \mathrm{~g}$ de cada amostra com $30 \mathrm{~mL}$ da solução estoque, sob agitação magnética por $1 \mathrm{~h}$, mantendo à mesma $25^{\circ} \mathrm{C} / 18 \mathrm{~h}$ no escuro; secagem realizada pelo processo de liofilização à $-55^{\circ} \mathrm{C}$.

As amostras modificadas com uréia seguiram a metodologia nas etapas adaptadas [22]: preparação de suspensões aquosas contendo $3 \mathrm{~g}$ das amostras e 50 $\mathrm{mL}$ de solução de uréia $(20 \% \mathrm{p} / \mathrm{p})$, seguida de agitação magnética por $20 \mathrm{~min}$ e $15 \mathrm{~min}$ em banho ultrasom. As soluções resultantes permaneceram em repouso por $24 \mathrm{~h}$. As amostras foram lavadas com $150 \mathrm{~mL}$ de água deionizada, $\mathrm{pH}=5,5$, envelhecimento por 5 dias, sendo posteriormente centrifugada à $2000 \mathrm{rpm} / 10 \mathrm{~min}$. O sobrenadante foi descartado e o resíduo seco em estufa por $24 \mathrm{~h} / 50{ }^{\circ} \mathrm{C}$. As nomenclaturas referentes às amostras naturais e modificadas encontram-se na Tabela I.

Tabela I - Identificação das amostras in natura e modificadas com ácido sulfúrico, ácido húmico e uréia.

[Table I - Identification of natural and modified samples with sulfuric acid, humic acid and urea.]

\begin{tabular}{cccccc}
\hline & Natural & $\begin{array}{c}\text { ácido } \\
\text { sulfúrico }\end{array}$ & $\begin{array}{c}\text { ácido } \\
\text { sulfúrico }\end{array}$ & $\begin{array}{c}\text { Ácido } \\
\text { húmico }\end{array}$ & uréia \\
\hline \multirow{2}{*}{} & $\mathrm{S} 2$ & $\mathrm{~S}_{2} \mathrm{H}_{25}$ & $\mathrm{~S}_{10} \mathrm{H}_{25}$ & $\mathrm{~S} 2 \mathrm{AH}$ & $\mathrm{S} 10 \mathrm{UH}$ \\
& & $\mathrm{S}_{2} \mathrm{H}_{5}$ & $\mathrm{~S}_{10} \mathrm{H}_{5}$ & & \\
\multirow{\Xi}{*}{} & $\mathrm{S} 10$ & $\mathrm{~S}_{2} \mathrm{H}_{1}$ & $\mathrm{~S}_{10} \mathrm{H}_{1}$ & $\mathrm{~S} 10 \mathrm{AH}$ & $\mathrm{S} 10 \mathrm{UH}$ \\
& & $\mathrm{S}_{2} \mathrm{H}_{15}$ & $\mathrm{~S}_{10} \mathrm{H}_{15}$ & & \\
\hline
\end{tabular}

\section{Métodos de caracterização dos materiais}

Fluorescência de raios X (FRX): utilizou-se o espectrômetro seqüencial Axios Mineral, tubo de raios $\mathrm{X}$ cerâmico, ânodo de Rh, PANalytical. Amostra em pastilha prensada (3 $\mathrm{g}$ para $0,6 \mathrm{~g}$ de parafina), com o programa IQ+Semiquant.

Difração de raios X (DRX): as análises foram realizadas em um difratômetro PANalytical X'Pert PW3050, radiação Cuka 1,540598, filtro de Ni, tempo de contagem $20 \mathrm{~s}$, corrente $40 \mathrm{~mA}$ e tensão $40 \mathrm{kV}$. As condições instrumentais foram: método do pó total - intervalo de $5^{\circ}$ a $75^{\circ}$ em $2 \theta$, passo $0,02^{\circ} / 2 \theta$ e tempo/passo $10 \mathrm{~s}$; fenda divergente $1 / 4^{\circ}$ e de anti-espalhamento $1 / 2^{\circ}$ e máscara $10 \mathrm{~mm}$. Método da fração argila - intervalo de $3^{\circ}$ a $35^{\circ}$ em $2 \theta$, passo $0,02^{\circ} / 2 \theta$, tempo/passo $10 \mathrm{~s}$, fenda divergente $1 / 8^{\circ} \mathrm{e}$ anti-espalhamento $1 / 4^{\circ}$.

Espectroscopia na região do Infravermelho por Transformada de Fourier (FTIR): as análises foram registradas em espectrofotômetro Thermo Electron Corporation IR-100 na faixa espectral de 400 a $4000 \mathrm{~cm}^{-1}$, com cristal de ZnSe. Cargas superficiais dos materiais: a carga superficial dos solos e/ou sedimentos foram estimadas a partir da diferença $\Delta \mathrm{pH}=\mathrm{pH}_{\mathrm{KCl}}-\mathrm{pH}_{\text {agua }}$, na qual $\mathrm{pH}_{\mathrm{KCl}}$ é obtido a partir de uma suspensão aquosa com relação sedimento-líquido 1:25 [22, 23].

Experimentos de adsorção: os testes de adsorção foram realizados a partir da preparação de uma solução estoque de molibdato de amônio $\left(\mathrm{NH}_{4}\right)_{6} \mathrm{Mo}_{7} \mathrm{O}_{24} \cdot 7 \mathrm{H}_{2} \mathrm{O}$ em concentração $200 \mathrm{mg} \mathrm{L}^{-1}$ e de suspensões aquosas contendo $0,5 \mathrm{~g}$ de cada amostra; adição de volumes adequados de solução estoque de molibdato a fim de perfazer o intervalo de concentração entre 5 à $50 \mathrm{mg} \mathrm{L}^{-1}$ em volume de $20 \mathrm{~mL}$; tempo de contato dinâmico por $2 \mathrm{~h}$ à temperatura ambiente; medidas de $\mathrm{pH}$ das suspensões antes e após o processo de adsorção; filtração das suspensões; medidas das concentrações de Mo nos filtrados por espectrometria de emissão ótica com plasma de ar indutivamente acoplado (ICP-OES).

Determinação das concentrações de equilíbrio: as medidas das concentrações de equilíbrio foram efetuadas por ICP-OES Vista- MPX CCD simultâneo (Varian, Mulgrave), configuração axial e equipado com um sistema de amostragem automático (SPS-5). O controle das condições operacionais do ICP OES foi feito com o software ICPExpert Vista.

Determinação das quantidades adsorvidas: as quantidades adsorvidas foram calculadas a partir das concentrações iniciais, pesos dos adsorventes, volume das suspensões aquosas e concentração de equilíbrio de molibdato, de acordo com a equação A:

$$
\mathrm{qe}=(\mathrm{Ci}-\mathrm{Ce}) \cdot v / \mathrm{m}
$$

na qual qe $=$ quantidade adsorvida no equilíbrio $\left(\mathrm{mg} \mathrm{g}^{-1}\right)$, $\mathrm{Ci}=$ concentração inicial do íon na solução $(\mathrm{mg} / \mathrm{L}), \mathrm{Ce}=$ concentração do íon no equilíbrio $(\mathrm{mg} / \mathrm{L}), \mathrm{V}=$ volume da solução suspensão aquosa $(\mathrm{L})$ e $\mathrm{m}=$ massa do adsorvente $(\mathrm{g})$.

Determinação das constantes de equilíbrio: as constantes de equilíbrio das reações de adsorção nas interfaces sólidassoluções são nomeadas como constantes de distribuição e são calculadas pela equação $\mathrm{B}$ :

$$
\mathrm{Kd}=\mathrm{qe} / \mathrm{Ce}
$$

Se qe é dado em $\mathrm{mg} \mathrm{g}^{-1}$ ou mol g ${ }^{-1}$ e Ce em mg L $\mathrm{L}^{-1}$ ou mol $\mathrm{L}^{-1}$, então a unidade de Keq é $\mathrm{L} \mathrm{g}^{-1}$.

Modelos de isotermas de adsorção: foram utilizados três tipos de modelos de adsorção:

Isoterma de Langmuir: este modelo permite estimar a capacidade máxima de adsorção do molibdato nas amostras; 
neste processo, cada sitio ativo irá interagir com uma espécie de adsorvato e a adsorção irá ocorrer em monocamadas. A forma não linearizada está expressa na equação $\mathrm{C}$ :

$$
\text { qe = Qmáx.KL.Ce / } 1+\text { KL.Ce }
$$

na qual Ce (mg.L $\left.\mathrm{L}^{-1}\right)$ é a concentração de equilíbrio do sobrenadante, KL a constante de afinidade de Langmuir e Qmáx $\left(\mathrm{mg} \mathrm{g}^{-1}\right)$ a capacidade máxima de adsorção.

Isoterma de Freundlich: neste modelo a concentração de adsorvato na superfície do adsorvente aumenta com a concentração dos adsorventes; este modelo se ajusta melhor em sistemas heterogêneos. A equação D segue um modelo exponencial.

$$
\mathrm{qe}=\mathrm{KF} . \mathrm{Ce} / \mathrm{n}
$$

na qual KF é a constante de Freundlich ( adimensional) e n o expoente de Freundlich (adimensional).

Isoterma de Sips ou Langmuir-Freundlich: este modelo apresenta comportamento semelhante às isotermas de Langmuir e Freundlich; se em baixas concentrações de iniciais de adsorvato $(\mathrm{Ce})$ for igual a zero, logo seguirá o modelo de Freundlich, caso seja diferente de zero, devido elevadas concentrações $(\mathrm{Ce})$, a isoterma seguirá o modelo de Langmuir. Este modelo é definido pela equação E:

$$
\mathrm{qe}=\frac{\text { Qmáx.(Ks.Ce }) / \mathrm{n}}{1+\mathrm{Ks} \cdot \mathrm{Ce} / \mathrm{n}(\mathrm{C})}
$$

na qual Qmáx ( $\mathrm{mg} \mathrm{g}^{-1}$ ) é a capacidade máxima de adsorção, $\mathrm{Ks}\left(\mathrm{mg} \mathrm{L}^{-1}\right)^{-1 / n}$

Cálculo do Fator de Separação: pelo cálculo do fator de separação (RL) é possível prever o tipo de espontaneidade no processo de adsorção, conforme a equação $\mathrm{F}$ :

$$
\mathrm{RL}=\frac{1}{1+\mathrm{KL} \cdot \mathrm{Ci}}
$$

A adsorção será favorável se $0<\mathrm{R}_{\mathrm{L}}<1$; desfavorável $\mathrm{R}_{\mathrm{L}}$ $>1$; irreversível $\mathrm{R}=0$ e linear $\mathrm{R}=1$.

\section{RESULTADOS E DISCUSSÃo}

A composição química das amostras naturais $\mathrm{S} 2$ e $\mathrm{S} 10$ encontra-se na Tabela II e indica que os teores de $\mathrm{SiO}_{2}, \mathrm{Al}_{2} \mathrm{O}_{3}$ e $\mathrm{Fe}_{2} \mathrm{O}_{3}$ em todas as amostras são similares aos encontrados para os silicatos aluminosos [16]. Os teores elevados de $\mathrm{SiO}_{2}$ estão relacionados à presença de argilominerais e quartzo, enquanto que os de $\mathrm{Al}_{2} \mathrm{O}_{3}$ estão associados à caulinita. Os elevados teores de $\mathrm{K}_{2} \mathrm{O}, \mathrm{Na}_{2} \mathrm{O}, \mathrm{MgO}$ e CaO estão relacionados com os minerais albita, calcita e feldspatos e são condizentes com os teores encontrados em solos acreanos [24]. Os valores obtidos para razão $\mathrm{SiO}_{2} / \mathrm{Al}_{2} \mathrm{O}_{3}$ são equivalentes ao da esmectita do tipo montmorilonita que apresenta razão superior a 2. Este aspecto sugere que nas amostras S2 e S10 $\left(\mathrm{SiO}_{2} / \mathrm{Al}_{2} \mathrm{O}_{3}: 3,52\right.$ e 2,84, respectivamente) predominam a montmorilonita.

\section{Difração de raios $X$}

Amineralogia das amostras naturais $\mathrm{S} 2 \mathrm{eS} 10$ identificadas por DRX é formada principalmente por esmectita $(1 / 2 \mathrm{Ca}, \mathrm{N}$ a) $)_{0,7}(\mathrm{Al}, \mathrm{Mg}, \mathrm{Fe})_{4}(\mathrm{Si}, \mathrm{Al})_{8} \mathrm{O}_{20}(\mathrm{OH})_{4}$, caulinita $\left(\mathrm{Al}_{4} \mathrm{Si}_{4} \mathrm{O}_{10}(\mathrm{OH})_{8}\right)$ e quartzo $\left(\mathrm{SiO}_{2}\right)$. Além destes minerais, na amostra $\mathrm{S} 2$ foram encontrados microclíneo $\left(\mathrm{KAlSi}_{3} \mathrm{O}_{8}\right)$, albita $\left(\mathrm{NaAlSi}_{3} \mathrm{O}_{8}\right)$ e calcita $\left(\mathrm{CaCO}_{3}\right)$. Todos os picos basais foram indexados por comparação com o banco de dados JCPDS-ICDD. O espaçamento basal da esmectita $\left(\mathrm{d}_{001} \sim 15 \AA\right.$ e $\mathrm{d}_{100} \sim 4,5 \AA$, observado em todas as amostras, sugere a predominância de uma esmectita cálcica na amostra $\mathrm{S} 2$, assim como traços de caulinita $\left(\mathrm{d}_{001} \sim 7,74 \AA\right)$. A identificação dos minerais não argilosos foi feita devido a presença dos espaçamentos basais, quartzo- $\alpha(\mathrm{d} \sim 3,36 \AA$ e $4,25 \AA)$, microclíneo $(\mathrm{d} \sim$ $3,23 \AA$ e $3,19 \AA)$, albita $(\mathrm{d} \sim 3,18 \AA)$ e calcita $(\mathrm{d} \sim 3,03$ $\AA$ ). As esmectitas são comuns na região do Acre, sendo encontradas entre os rios Purus e Jurúa; as ilitas ocorrem freqüentemente entre os rios Laco e Caeté; a caulinita não é comumente encontrada nestes sedimentos e o quartzo é o mineral mais abundante em argilas provenientes desta região $[24,25]$.

O difratograma da amostra S2, Fig. 1, indica minerais de argila, tais como esmectita (JCPDS 02-0008) devido $\mathrm{d}_{001} \sim$ $14,8 \AA \mathrm{e} \mathrm{d}_{002} \sim 4,5 \AA$, além de um pico mais intenso em torno $4,26 \AA$, do pico em $1,495 \AA$, referente a reflexão 060 , indica ser uma esmectita do tipo montmorilonita. Foram observados caulinita (JCPDS 78-2110) $\mathrm{d}_{001} \sim 7,11 \AA \AA$, quartzo (JCPDS 850798) $\mathrm{d}_{011} \sim 3,34 \AA$ e $\mathrm{d}_{100} \sim 4,26 \AA$, além de albita (JCPDS 09-0466) $\mathrm{d}_{002} \sim 3,19 \AA$, microclíneo (JCPDS 22-0675) $\mathrm{d}_{220} \sim$ $3,24 \AA$ e calcita $\mathrm{d}_{104} \sim 3,03 \AA$ (JCPDS 72-1652). Os minerais primários albita e microclíneo, assim como calcita, não foram observados na amostra S10, Fig. 1, mas somente esmectita (JCPDS 29-1497) com $\mathrm{d}_{001} \sim 14,93 \AA \mathrm{Ae}_{002} \sim 4,48 \AA$, caulinita (JCPDS 14-164) $\mathrm{d}_{001} \sim 7,28 \AA$ e quartzo (JCPDS 85-0798) $\mathrm{d}_{011}$

\begin{tabular}{|c|c|c|c|c|c|c|c|c|c|c|c|c|c|}
\hline $\begin{array}{l}\text { Amostras } \\
(\% \mathrm{p} / \mathrm{p})\end{array}$ & $\begin{aligned} \mathrm{SiO}_{2}^{*} \\
\end{aligned}$ & $\mathrm{Al}_{2} \mathrm{O}_{3}^{*}$ & $\mathrm{Fe}_{2} \mathrm{O}_{3}$ & $\mathrm{MgO}$ & $\mathrm{CaO}$ & $\mathrm{TiO}_{2}$ & $\underset{2}{\mathrm{NaO}}$ & $\mathrm{K} \mathrm{O}_{2}$ & $\mathrm{PO}_{2} \mathrm{O}_{5}$ & $\mathrm{SO}_{3}$ & $\mathrm{ZrO}_{2}$ & $\mathrm{PF}$ & Total \\
\hline S2 & 53,92 & 15,28 & 7,41 & 1,99 & 4,33 & 0,90 & 0,48 & 2,06 & 0,14 & 0,07 & 0,03 & 13,34 & 99,95 \\
\hline $\mathrm{S} 10$ & 51,98 & 18,25 & 8,35 & 1,08 & 0,31 & 0,95 & 0,21 & 2,04 & 0,08 & 0,11 & 0,03 & 16,59 & 99,98 \\
\hline Média & 52,95 & 16,76 & 7,88 & 1,53 & 2,32 & 0,92 & 0,34 & 2,05 & 0,11 & 0,09 & 0,03 & 14,96 & 99,94 \\
\hline
\end{tabular}
$\sim 3,35 \AA$ e d $_{100} \sim 4,26 \AA$. Tabela III.

Tabela II - Composição química (\% p/p) das amostras S2 e S10.

[Table II - S2 and S10 chemical composition (wt.\%).] 


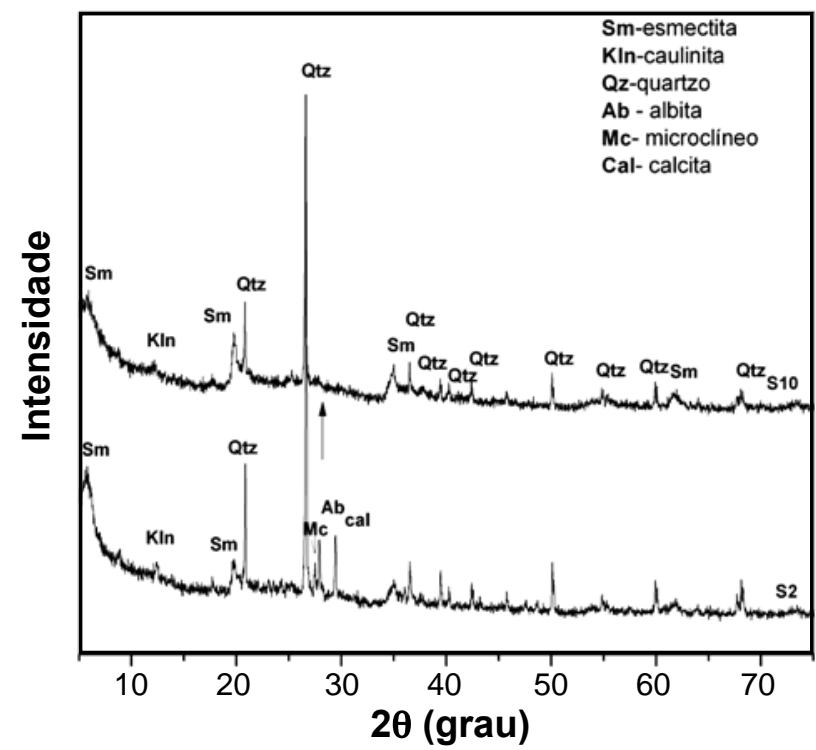

Figura 1: Difratogramas de raios X das amostras S2 e S10 (Sm - esmectita; Kln - caulinita; Qtz - quartzo; Mc -microclíneo; Ab albita; Cal - calcita).

[Figure 1: X-ray diffraction patterns of $S 2$ and S10 samples (Sm smectite; Kln - kaolinite; Qtz - quartz; Mc - microcline; Ab - albite; Cal - calcite.]

Tabela III - Principais picos basais utilizados na identificação mineralógica nas amostras S2 e S10.

[Table III - Identification of main mineralogy basal peaks of samples S2and S10.]

\begin{tabular}{ccccc}
\hline Amostra & Mineral & hkl & $2 \theta$ & $\mathrm{d}[\AA]$ \\
\hline & caulinita & 001 & 12,4 & 7,11 \\
& & 001 & 5,79 & 15,17 \\
& & & \\
& & 300 & 61,98 & $1,49^{*}$ \\
S2 & & & & \\
& quartzo & & 26,6 & 3,34 \\
& & 100 & 20,83 & 4,26 \\
& albita & 002 & 27,9 & 3,19 \\
& microclíneo & 220 & 27,5 & 3,23 \\
& calcita & 104 & 29,4 & 3,03 \\
\hline Amostra & Mineral & Hkl & $2 \theta$ & $\mathrm{d}[\AA]$ \\
\hline \multirow{5}{*}{ S10 } & caulinita & 001 & 12,14 & 7,28 \\
& esmectita & 001 & 5,91 & 14,93 \\
& & 002 & 19,79 & 4,48 \\
& & 300 & 61,91 & $1,49^{*}$ \\
& & & & \\
& & 011 & 26,59 & 3,35 \\
& & 100 & 20,80 & 4,26 \\
\hline
\end{tabular}

*-Reflexão 060, típica de esmectita montmorilonita.

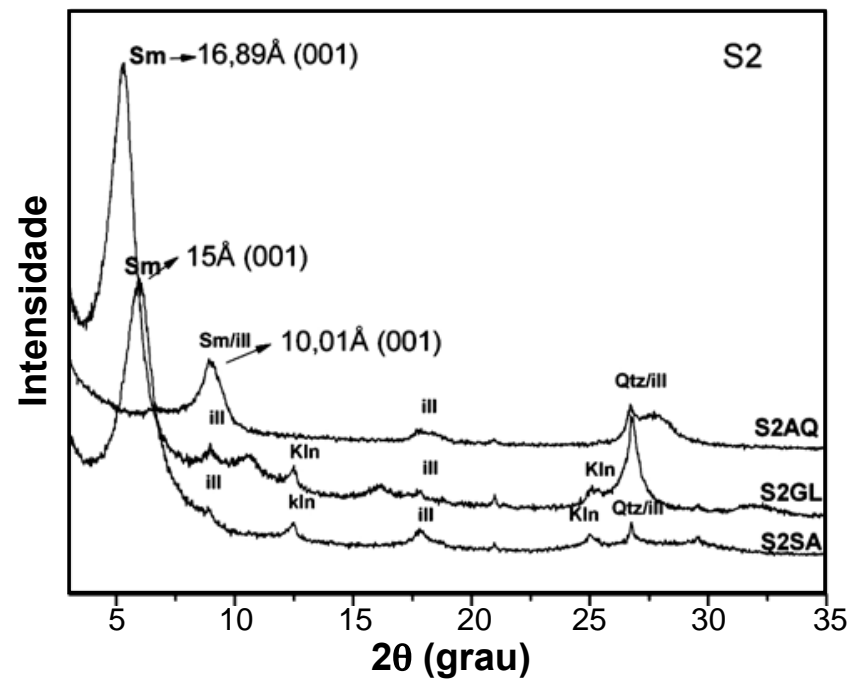

Figura 2: Difratogramas de raios $\mathrm{X}$ referentes a fração argila da amostra S2AQ (Aquecida à $500{ }^{\circ} \mathrm{C}$ ), S2Gly (Glicolada) e S2AD (Seca ao ar): Sm - esmectita; Kln - caulinita; Qtz - quartzo e ill - ilita. [Figure 2: X-ray diffraction patterns of fraction clay $S 2 A Q$ (heated at $500^{\circ} \mathrm{C}$ ), S2Gly (glycolated) and $S 2 A D$ (air-dried). (Sm smectite; Kln - kaolinite; Qtz - quartz; Mc - microcline; ill - illite.]

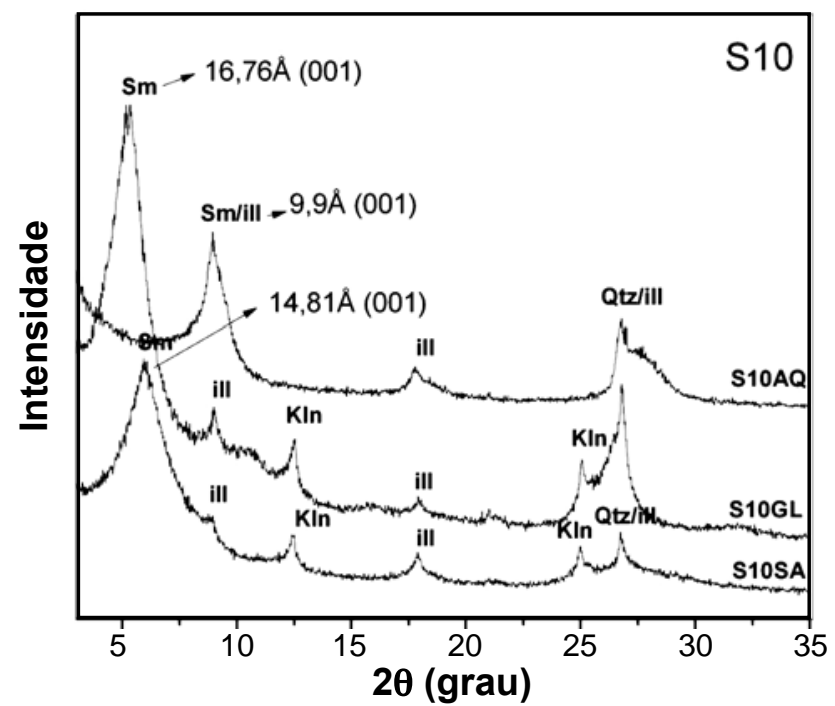

Figura 3: Difratogramas de raios $X$ da fração argila da amostra S10AQ (aquecida a $500{ }^{\circ} \mathrm{C}$ ), S10Gly (Glicolada) e S10AD (seca ao ar): Sm - esmectita; Kln - caulinita; Qtz - quartzo e ill - ilita.

[Figure 3: X-ray diffraction patterns of fraction clay $S 10 A Q$ (heated at $500{ }^{\circ} \mathrm{C}$ ), S10Gly (glycolated) and S10AD (air-dried). (Sm - smectite; Kln - kaolinite; Qtz - quartz; ill - illite.]

Nos difratogramas referentes à fração $<2 \mu \mathrm{m}$ das amostras S2 e S10 (Figs. 2 e 3) foi confirmada a presença de esmectita pelos seguintes aspectos: pico $d_{001} \sim 15 \AA$ nas amostras secas ao ar (AD); expansão das camadas octaédricas, indicada pelo aumento do pico $\mathrm{d}_{001} \sim 15 \AA$ para $\sim 17 \AA$ Å quando a amostra é saturada com etilenoglicol (Gly); contração indicada pelo pico $\mathrm{d}_{001} \sim 10 \AA$ quando a amostra é calcinada a $500{ }^{\circ} \mathrm{C}$. A possível presença de ilita nas amostras deve-se ao aparecimento da reflexão $\mathrm{d}_{001} \sim 10 \AA \mathrm{m}$ todas as 
etapas. A caulinita apresenta pico $7 \AA$ e $3,5 \AA$ quando seca ao ar e glicolada, porém quando calcinada há o colapso da estrutura e desaparecimento destas reflexões.

A indexação dos picos por DRX e a análise química dos elementos maiores obtidas por FRX para as amostras S2 e S10 comprovam a presença de esmectita, caulinita e quartzo como minerais principais. Os valores pouco elevados para $\mathrm{K}_{2} \mathrm{O}, \mathrm{Na}_{2} \mathrm{O}$ e $\mathrm{CaO}$ corroboram com a presença dos minerais albita, microclineo e calcita na amostra S2. A amostra S10 apresentou menor teor de impurezas (minerais interferentes como albita, microclineo e calcita), sendo selecionada para os testes de modificação com ácido sulfúrico, ácido húmico e uréia. A amostra S10 foi selecionada para os ensaios de modificação química (orgânica e inorgânica), pois apresentou maior percentual da fração argila, menor teor de quartzo $\left(\mathrm{SiO}_{2}\right)$ e reduzido teor de minerais acessórios como: albita, microclineo e calcita.

No difratograma da amostra modificada com ácido sulfúrico S10H15 (Fig. 4) foram observadas modificações no pico $\mathrm{d}_{001} \sim 15 \AA$ da esmectita. Conforme há aumento na concentração do ácido, ocorre o desaparecimento do plano 001 da esmectita e variação no plano basal 001 da caulinita. $\mathrm{O}$ ataque ácido não afetou a estrutura do quartzo, porém evidenciaram minerais como ilita e albita.

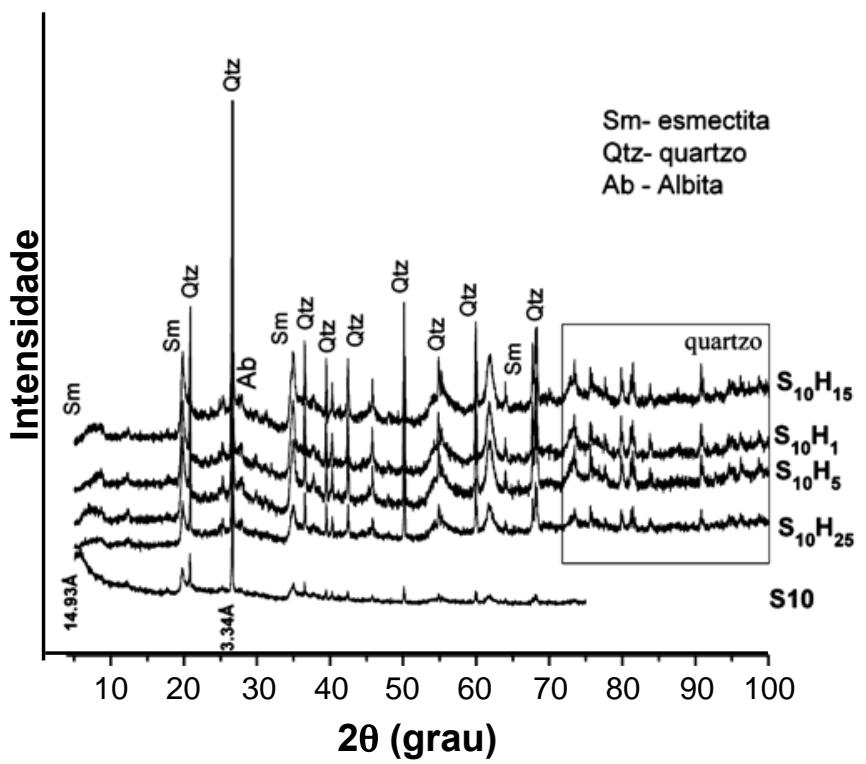

Figura 4: Difratogramas de raios X da amostra S10 modificada com ácido sulfúrico nas concentrações $\left(0,25 ; 0,5 ; 1\right.$ e $\left.1,5 \mathrm{~mol} \mathrm{~L}^{-1}\right)$ : Sm esmectita; Qtz - quartzo, Ab - albita.

[Figure 4: X-ray diffraction patterns of sample S10 modified with sulfuric acid on concentrations $\left(0.25 ; 0.5 ; 1\right.$ and $\left.1.5 \mathrm{~mol} \mathrm{~L}^{1}\right)$ : Sm smectite; Qtz - quartz, Ab - albite].

Pode-se concluir que o ataque ácido promove a inserção dos íons $\mathrm{H}_{3} \mathrm{O}^{+}$entre as camadas 2:1 devido à troca iônica dos cátions interlamelares $\left(\mathrm{Na}^{+}\right.$ou $\left.\mathrm{Ca}^{2+}\right)$, além de promover a destruição das bordas das lamelas, expondo $\mathrm{Al}^{3+}$ ou $\mathrm{Mg}^{2+}$ da folha octaedral, quando a lixiviação é aliada ao tratamento térmico $\left(90^{\circ} \mathrm{C}\right)$ há perda de cristalinidade do material ao longo do plano 001 e formação de um material amorfo.

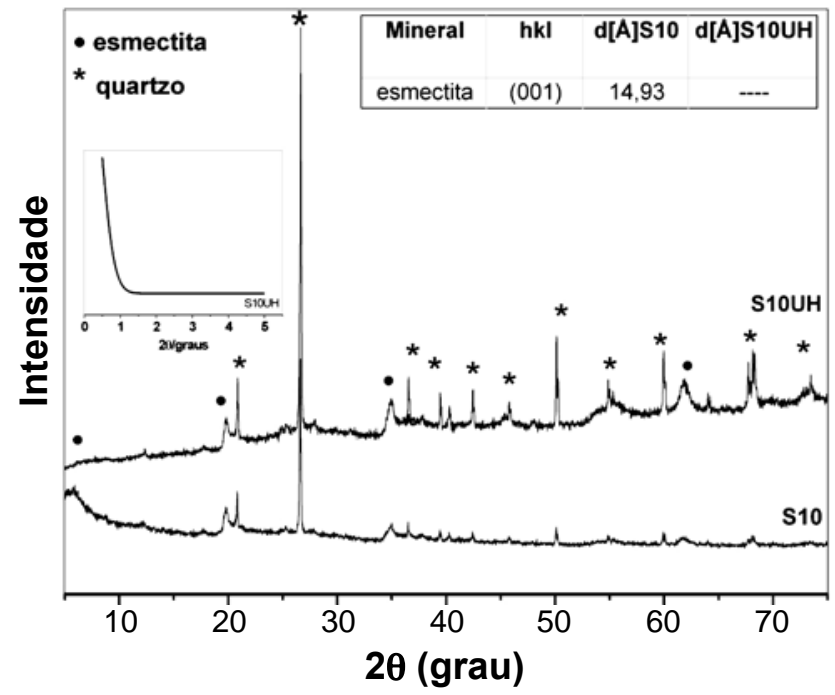

Figura 5: Difratogramas de raios X da amostra S10 e S10UH: Sm - esmectita; Kln - caulinita; Qtz - quartzo.

[Figure 5: X-ray diffraction patterns of sample S10 and S10UH: Sm - smectite; Kln - kaulinite; Qtz - quartz.]

Porém os grupos $\mathrm{SiO}_{4}$ permanecem intactos $[18,19]$.

No DRX da amostra S10UH, Fig. 5, a inserção da uréia promoveu o desaparecimento do plano 001 da esmectita, evidenciado por DRX em baixo ângulo. Esse comportamento pode ser associado devido às interações químicas das moléculas de uréia (íons $\mathrm{NH}_{4}^{+}$) devido a uma possível inclinação perpendicular aos planos de átomos nas lamelas da esmectita [26]. O quartzo não sofre alteração.

Nos difratogramas da amostra S10AH, Fig. 6, houve um aumento do valor referente ao espaçamento basal de 14,93 $\AA$ para $39,38 \AA$; este resultado sugere que embora varie a quantidade de grupos orgânicos que interage, o tamanho da cadeia carbônica permite um constante afastamento das

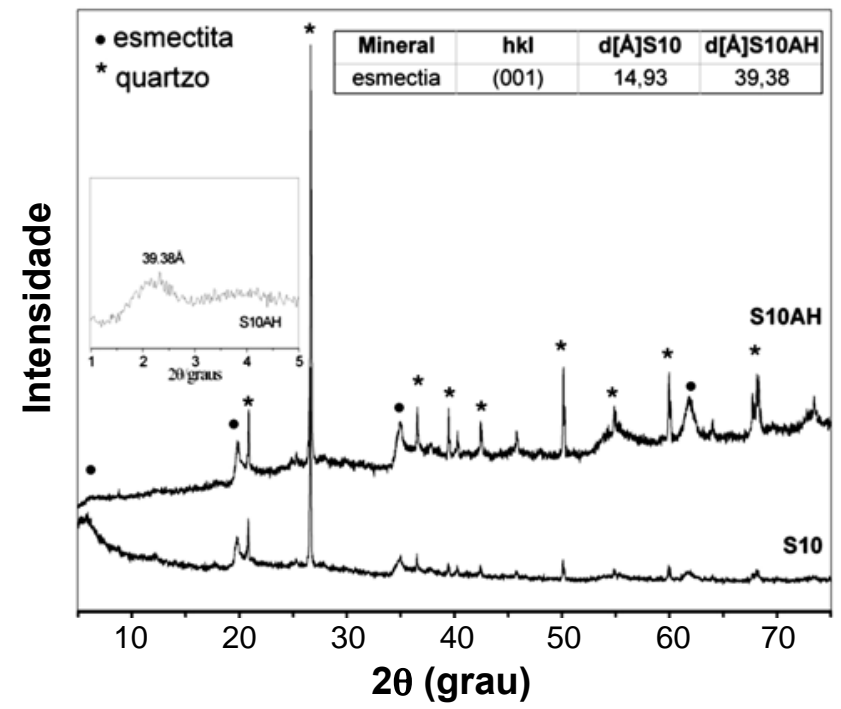

Figura 6: Difratogramas de raios X da amostra S10 e S10AH: Sm - esmectita; Kln - caulinita; Qtz - quartzo.

[Figure 6: X-ray diffraction patterns of sample S10 and S10AH: Sm - smectite; Kln - kaulinite; Qtz - quartz]. 
lamelas da esmectita. Os picos de quartzo permanecem inalterados.

\section{Espectros FTIR}

Nos espectros FTIR das amostras naturais (Fig. 7) são observadas bandas de absorção típicas dos argilominerais (esmectita/caulinita) $\sim 3620 \mathrm{~cm}^{-1}$, referentes as vibrações de estiramentos dos grupos $\mathrm{OH}$ ligados ao $\mathrm{Al}^{3+}$, associados aos grupos da esmectita e caulinita [21, 22], a banda $3460 \mathrm{~cm}^{-1}$ perceptível na amostra $\mathrm{S} 10$ foi atribuída á vibração de estiramento de água de hidratação nos argilominerais, tais como esmectita (montmorilonita, ilita e caulinita). A banda em torno de $1432 \mathrm{~cm}^{-1}$ foi associada a presença de calcita, bandas em torno de 1620 a $1650 \mathrm{~cm}^{-1}$ são correspondentes à vibração de deformação da molécula de água; bandas na região próxima a $790 \mathrm{~cm}^{-1}$ são características de argilominerais, no qual são atribuídos ao modo de deformação angular do grupo Al-O-Si. A banda em torno de $870 \mathrm{~cm}^{-1}$ corrobora com os elevados teores de ferro obtidos por FRX. A presença de quartzo nas amostras é reforçada nos espectros FTIR pelos dubletos em 778/779 $\mathrm{cm}^{-1}$, as deformações angulares de Si-O-Al e Si-O-Fe são referentes as bandas em torno de 690 e $470 \mathrm{~cm}^{-1}$ respectivamente.

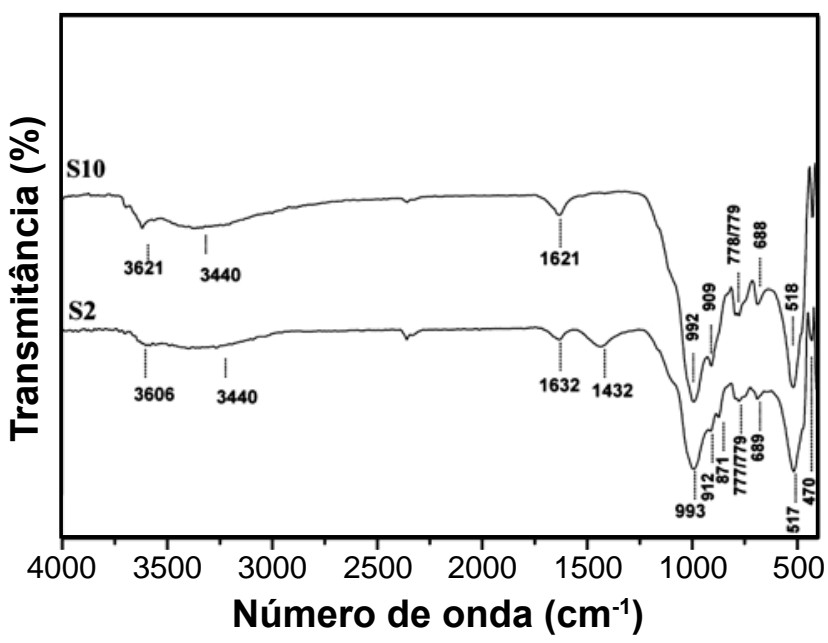

Figura 7: Espectros FTIR para as amostras S2 e S10.

[Figure 7: FTIR spectra of $S 2$ and S10 samples].

O espectro FTIR da amostra natural S10 e modificada com ácido sulfúrico (Fig. 8) corrobora com os dados obtidos por DRX, as principais bandas de absorção associadas ao estiramento e deformação dos grupos $\mathrm{OH}$ diminuem de intensidade conforme há aumento da concentração do ácido. Este resultado é representado pela presença de bandas $3600 \mathrm{~cm}^{-1}$ referente ao estiramento $\mathrm{OH}$ estrutural típico da montmorilonita, $\sim 3400 \mathrm{~cm}^{-1}$ referente ao estiramento $\mathrm{OH}$ da $\mathrm{H}_{2} \mathrm{O}$, as bandas em torno de $910 \mathrm{~cm}^{-1}$ e $520 \mathrm{~cm}^{-1}$ são referentes a deformação $\mathrm{Al}-\mathrm{OH}-\mathrm{Al}$ e $\mathrm{Al}-\mathrm{O}-\mathrm{Si}$ respectivamente.

Nas amostras S10AH e S10UH, (Fig. 9), são observados que as bandas em torno de $3620 \mathrm{~cm}^{-1}$ referente ao estiramento do grupo hidroxila ligado ao $\mathrm{Al}^{3+}$ na montmorilonita são

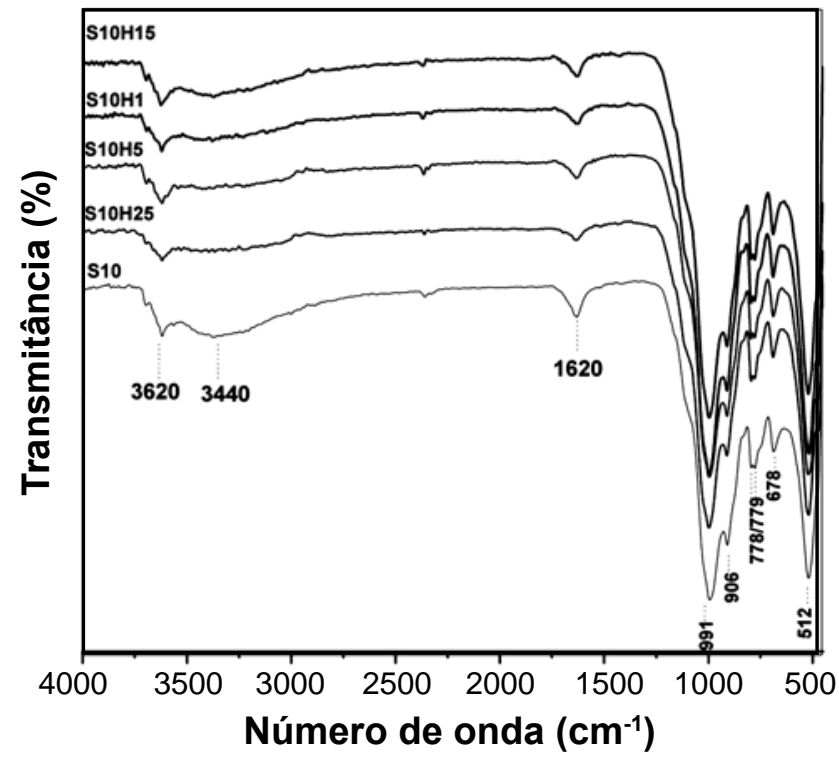

Figura 8: Espectros FTIR da amostra natural S10 e modificadas com ácido sulfúrico (S10H15).

[Figure 8: FTIR spectra of natural sample S10 and modified with sulfuric acid (S1OH15)].

bastante afetadas com diminuição em sua intensidade, assim como a banda em torno de $3440 \mathrm{~cm}^{-1}$ atribuída à vibração de estiramento das moléculas de água de hidratação típica da montmorilonita. Os grupamentos das hidroxilas superficiais são deslocados de $909 \mathrm{~cm}^{-1}$ na amostra S10 para $912 / 913 \mathrm{~cm}^{-1}$ nas amostras S10UH e S10AH, respectivamente. Na banda torno de $992 \mathrm{~cm}^{-1}$ também é observado um deslocamento para $1002 / 1003 \mathrm{~cm}^{-1}$, em ambas as amostras, referente à vibração $\mathrm{Al}_{2}-\mathrm{OH}$ na camada dioctáedrica da esmectita [27, 28]. Tal comportamento pode indicar que a inserção do composto orgânico promoveu o afastamento das lamelas e possível reação com as hidroxilas da superfície externa/ bordas da esmectita.

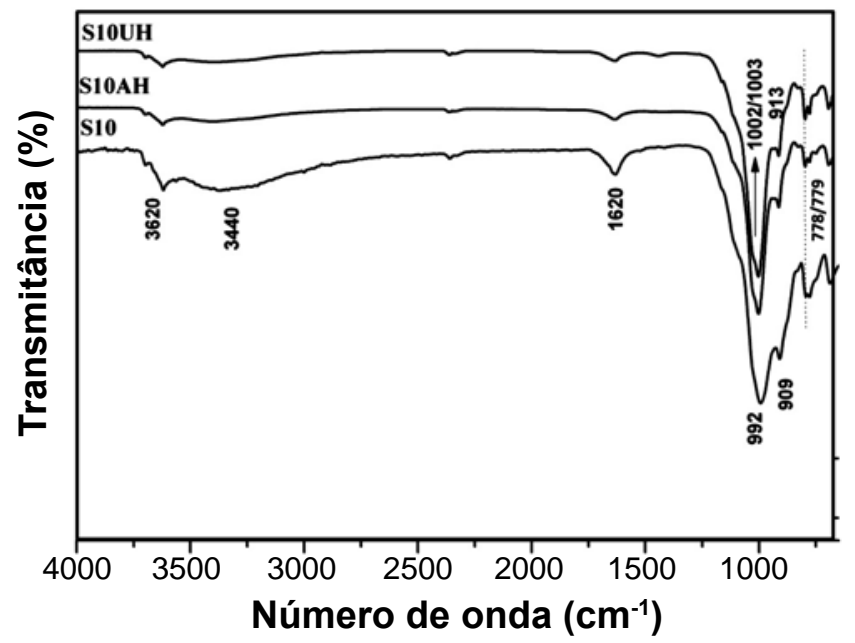

Figura 9: Espectros FTIR da amostra natural S10 e modificadas com Ácido Húmico (S10AH), Uréia (S10UH).

[Figure 9: FTIR spectra of natural sample S10 and modified with humic acid (S10AH) and urea (S10UH)]. 


\section{Carga superficial}

A estimativa da carga liquida do solo obtido para as amostras S2 e S10, indicam que há predominância de cargas negativas na superfície do sólido, favorecendo a adsorção de cátions. Em minerais de argila quando em suspensão aquosa, devido a presença de hidroxilas na superfície desses minerais, podem ser criados cargas negativas ou positivas por protonação ou desprotonação desses grupamentos, desta forma, a adsorção do ânion pode ocorrer nessa interface ou nas bordas dos minerais.

\section{Testes de adsorção}

Os testes de adsorção foram realizados na amostra natural S10 e nas amostras modificadas com uréia (S10UH), ácido húmico (S10AH) e ácido sulfúrico (S10H15), com intuito de se avaliar em qual amostra é mais eficiente a adsorção de molibdato.

Avaliação da Concentração Equilíbrio (Ce) Vs. Quantidade Adsorvida (qe)

$\mathrm{Na}$ amostra S10H15 (Fig. 10) a quantidade adsorvida de $\mathrm{MoO}_{4}^{2-}$ é proporcional ao aumento da concentração, atingindo o máximo em $4,59 \mathrm{mg} / \mathrm{g}$, comparando-se os valores de $\mathrm{q}_{\mathrm{e}}$ obtidos para todas as amostras é possível inferir que a amostra $\mathrm{S} 10 \mathrm{H} 15$ foi a mais eficiente no processo de adsorção. $\mathrm{Na}$ amostra $\mathrm{S} 10$ a adsorção de molibdato é favorecida em concentrações mais elevadas. Apesar das amostras S10UH e S10AH possuírem comportamento similar, a modificação orgânica com ácido húmico mostrouse mais eficiente no processo de adsorção que a amostra com uréia.

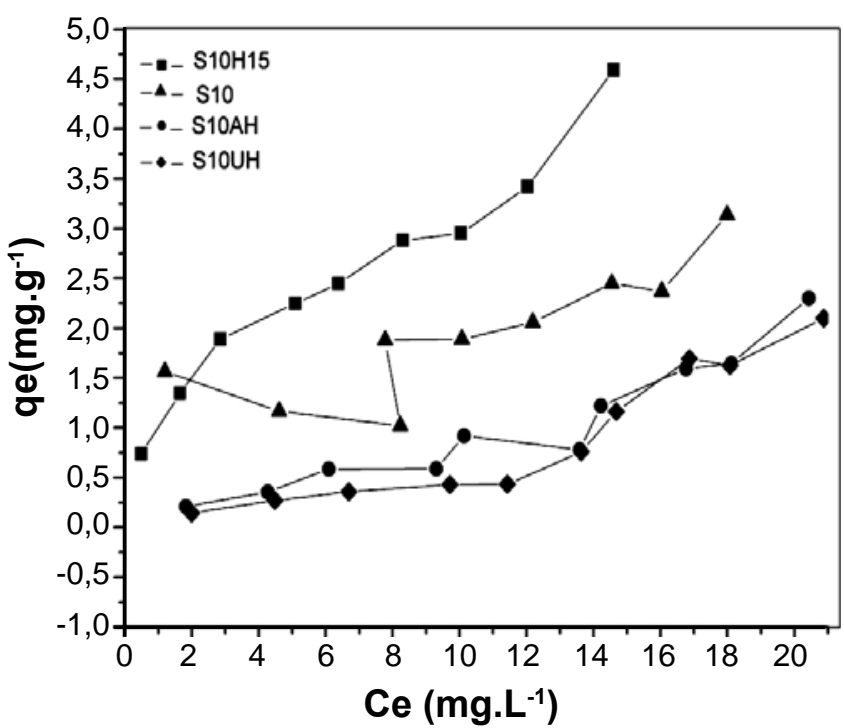

Figura 10: Relação entre a quantidade adsorvida e a concentração de equilíbrio de molibdênio nas amostras S10, S10H15; S10UH e S10AH.

[Figure 10: Relationship between the adsorption amount and $\mathrm{MoO}_{4}^{2-}$ amount on S10; S10H15; S10UH and S10AH.]

\section{Efeitos do pH(eq) Vs. a Quantidade Adsorvida (qe)}

A adsorção do $\mathrm{MoO}_{4}{ }^{2-} \mathrm{em}$ todas as amostras ocorre na faixa de pH 3 a 5,5 (Fig. 11), a maior quantidade adsorvida é observada em $\mathrm{pH} \sim 3$ na amostra $\mathrm{S} 10 \mathrm{H} 15$, como a adsorção de $\mathrm{MoO}_{4}^{2-}$ é dependente do $\mathrm{pH}$ do solo, do teor de $\mathrm{Fe}$ e $\mathrm{Al}$ e da fração argila, a lixiviação com ácido sulfúrico reduz essas características e forma um material elevado poder adsortivo. $\mathrm{Na}$ amostra S10 conforme há aumento no pH menos eficiente é a adsorção do íon, fato observado também para as amostras S10UH e S10AH. Este resultado é condizente com a primeira dissociação do ácido mobilídico $(\mathrm{pH} \approx 4,5)$ [29].

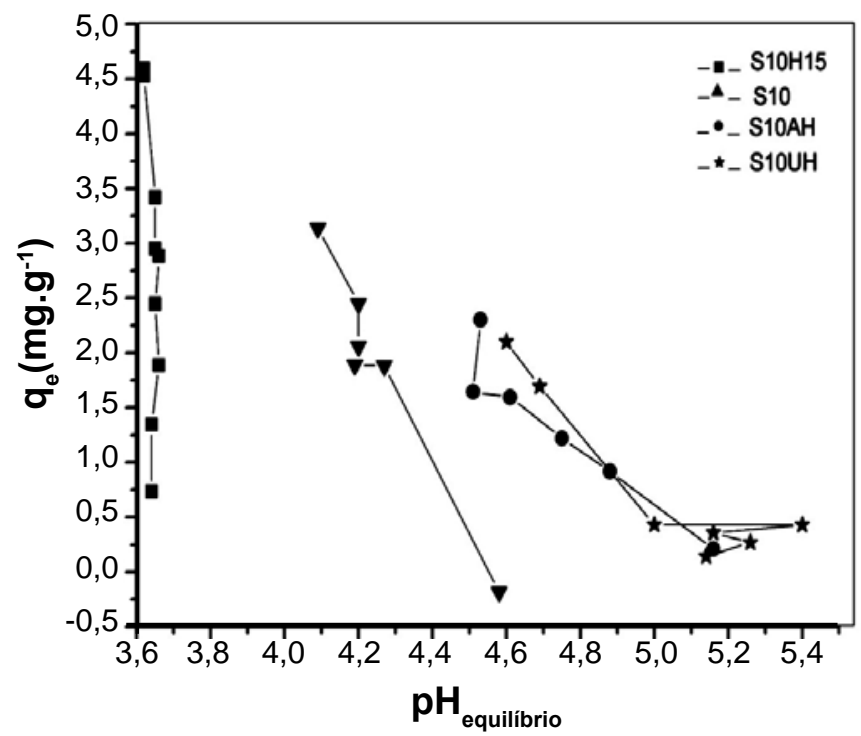

Figura 11: Relação entre o $\mathrm{pH}$ equilíbrio e a quantidade adsorvida nas amostras S10, S10H15; S10UH e S10AH.

[Figure 11: Relationship between equilibrium $\mathrm{pH}$ and adsorption amount in the samples S10; S1OH15; S10UH and S1OAH].

\section{Isotermas de adsorção}

Os ajustes matemáticos definidos pelos parâmetros $\left(\mathrm{K}_{\mathrm{L}}, \mathrm{K}_{\mathrm{f}}\right)$ das isotermas de adsorção, avaliação de $\mathrm{C}_{\mathrm{e}} v s . \mathrm{q}_{\mathrm{e}}$, $\mathrm{pH}$ vs. $\mathrm{q}_{\mathrm{e}}$ e Qmáx (sips) indicam que a amostra $\mathrm{S} 10 \mathrm{H} 15$ é a mais eficiente na adsorção de $\mathrm{MoO}_{4}{ }^{2-}$ em comparação as amostras S10, S10AH e S10UH.

A amostra S10H15 (Fig. 12) ajustou-se adequadamente aos modelos de Langmuir e Freundlich, assim como apresentou bons valores de correlação linear, Langmuir $\left(\mathrm{R}^{2}\right.$ $=0,84)$ Freundlich $\left(\mathrm{R}^{2}=0,87\right)$ e Sips $\left(\mathrm{R}^{2}=0,83\right)$. Os maiores valores referentes aos parâmetros $\mathrm{K}_{\mathrm{L}}, \mathrm{K}_{\mathrm{f}}$ (capacidade de adsorção e energia de ligação) foram encontrados para esta amostra.

Estes resultados indicam que a elevada capacidade de adsorção do ânion em estudo na amostra S10H15, deve-se a possível formação de complexos, reações de condensação e formação de uma série de polimolibdatos favorecidos em $\mathrm{pH}<4$ [2] e não apenas a interações eletrostáticas. Logo, o processo de ativação ácida e conseqüente amorfização da estrutura, gerou um material amorfo com elevado poder de 


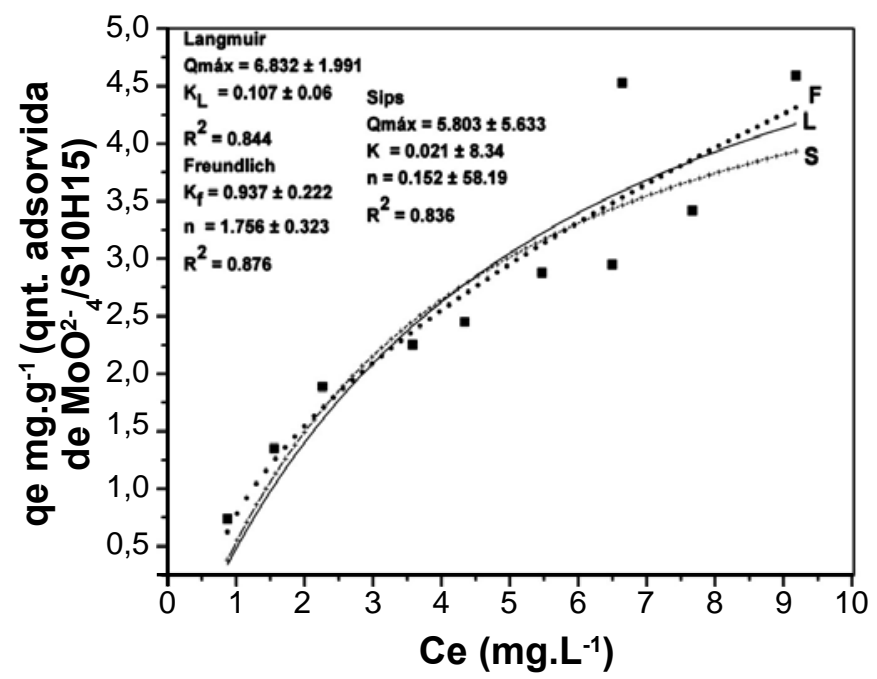

Figura 12: Amostra S10H15: modelos de isotermas de adsorção de $\mathrm{MoO}_{4}^{2-}$, à $25^{\circ} \mathrm{C}$, massa $0,05 \mathrm{~g}$ e tempo de contato: $2 \mathrm{~h}$.

[Figure 12: S10H15 Sample: Models of adsorption isotherms $\mathrm{MoO}_{4}^{2-}\left(25^{\circ} \mathrm{C}, 0.05 \mathrm{~g}, 2 \mathrm{~h}\right) \mathrm{]}$.

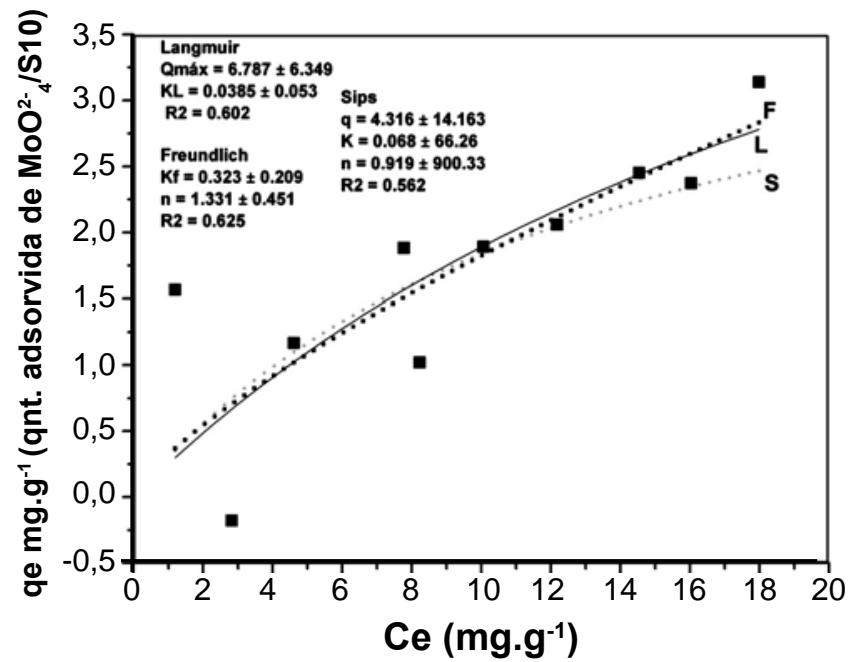

Figura 13: Amostra S10: modelos de isotermas de adsorção de $\mathrm{MoO}_{4}{ }^{2-}$, à $25^{\circ} \mathrm{C}$, massa $0,05 \mathrm{~g}$ e tempo de contato: $2 \mathrm{~h}$.

[Figure 13: S10 Sample: Models of adsorption isotherms $\mathrm{MoO}_{4}^{2-}$ $\left.\left(25^{\circ} \mathrm{C}, 0.05 \mathrm{~g}, 2 \mathrm{~h}\right)\right]$.

Tabela IV - Parâmetros de adsorção segundo o modelo de Langmuir, Freundlich e Sips para as amostras S10, S10H15, S10UH e S10AH.

[Table IV - Parameters of adsorption by Langmuir, Freundlich and Sips models for samples S10, S10H15, S10UH and S10AH.]

\begin{tabular}{|c|c|c|c|c|c|c|}
\hline Amostras & Modelos & Parâmetro 1 & Parâmetro 2 & Parâmetro 3 & $\mathbf{R}^{2}$ & Kd \\
\hline \multirow{3}{*}{ S10 } & Langmuir & $\mathrm{q}_{\text {máx }}=6,787 \pm 6,3$ & $\mathrm{~K}_{\mathrm{L}}=0,038 \pm 0,05$ & --- & 0,602 & \multirow{3}{*}{0,271} \\
\hline & Freundlich & $\mathrm{K}_{\mathrm{F}}=0,323 \pm 0,2$ & $\mathrm{n}_{\mathrm{F}}=1,331 \pm 0,4$ & --- & 0,625 & \\
\hline & Sips & $\mathrm{q}_{\operatorname{máx}}=4,316 \pm 14,1$ & $\mathrm{~K}_{\mathrm{s}}=0,068$ & $\mathrm{~b}_{\mathrm{s}}=0,919$ & 0,526 & \\
\hline \multirow{3}{*}{ S10H15 } & Langmuir & $\mathrm{q}_{\text {máx }}=6,832 \pm 1,9$ & $\mathrm{~K}_{\mathrm{L}}=0,107 \pm 0,06$ & --- & 0,844 & \multirow{3}{*}{0,549} \\
\hline & Freundlich & $\mathrm{K}_{\mathrm{F}}=0,937 \pm 0,2$ & $\mathrm{n}_{\mathrm{F}}=1,756 \pm 0,3$ & --- & 0,876 & \\
\hline & Sips & $\mathrm{q}_{\text {máx }}=5,803 \pm 5,6$ & $\mathrm{~K}_{\mathrm{s}}=0,021$ & $\mathrm{bs}=0,152$ & $0,8.36$ & \\
\hline \multirow{3}{*}{ S10AH } & Langmuir & $\mathrm{q}_{\text {máx }}=8,926 \pm 15,4$ & $\mathrm{~K}_{\mathrm{L}}=0,012 \pm 0,02$ & --- & 0,836 & \multirow{3}{*}{0,008} \\
\hline & Freundlich & $\mathrm{K}_{\mathrm{F}}=0,026 \pm 0,01$ & $\mathrm{n}_{\mathrm{F}}=0,693 \pm 0,1$ & --- & 0,918 & \\
\hline & Sips & $\mathrm{q}_{\text {máx }}=3,418 \pm 19,9$ & $\mathrm{~K}_{\mathrm{s}}=0,014$ & $\mathrm{bs}=0,352$ & 0,748 & \\
\hline \multirow{3}{*}{ S10UH } & Langmuir & $\mathrm{q}_{\text {máx }}=10,714$ & $\mathrm{~K}_{\mathrm{L}}=0,008 \pm 0,03$ & --- & 0,771 & \multirow{3}{*}{0,006} \\
\hline & Freundlich & $\mathrm{K}_{\mathrm{F}}=0,005 \pm 0.003$ & $\mathrm{n}_{\mathrm{F}}=0,503 \pm 0,06$ & --- & 0,947 & \\
\hline & Sips & $\mathrm{q}_{\text {máx }}=2,904 \pm 18,6$ & $\mathrm{~K}_{\mathrm{s}}=-0,007$ & $\mathrm{Bs}=-0,149$ & 0,638 & \\
\hline
\end{tabular}

adsorção, associado provavelmente a formação da fase sílica amorfa.

$\mathrm{Na}$ amostra S10 (Fig. 13) observa-se que as isotermas de Freundlich e Langmuir se ajustam adequadamente aos pontos estudados, porém pode-se inferir que há regiões distintas de adsorção. Os ajustes de alguns pontos observados na amostra podem indicar a presença de sítios altamente energéticos, o que parece indicar que concentrações acima de 10 ppm representam a melhor faixa no processo de adsorção. Os baixos valores dos coeficientes de correlação $\left(\mathrm{R}^{2}\right)$, Langmuir $\left(\mathrm{R}^{2}=0,6\right)$ Freundlich $\left(\mathrm{R}^{2}=0,62\right)$ e Sips $\left(\mathrm{R}^{2}=0,56\right)$ apontam que não há uma boa correlação aos pontos na amostra total. Tabela IV. A presença de diversos minerais na amostra pode contribuir para sítios de adsorção diferenciados.
Os resultados obtidos para o modelo de Langmuir relacionados a capacidade de adsorção $\left(\mathrm{q}_{\text {máx }}-4,31 \mathrm{mg} / \mathrm{g}\right)$ e energia de ligação, indicam que o solo natural adsorve uma grande quantidade de $\mathrm{MoO}_{4}{ }^{2-}$, porém a energia que o mantém adsorvido é fraca. Uma expressiva quantidade deste ânion pode ficar dispersa na solução e, formar complexos.

Os resultados obtidos a partir dos valores de correlação linear para Langmuir $\left(\mathrm{R}^{2}=0,77\right)$ Freundlich $\left(\mathrm{R}^{2}=0,94\right) \mathrm{e}$ Sips $\left(\mathrm{R}^{2}=0,63\right)$ para a amostra S10UH (Fig. 14) indicam que o modelo de Freundlich é o mais adequado para descrever o comportamento de adsorção. Nesta amostra, observam-se regiões distintas de adsorção, a linearidade dos pontos sugere que a maior adsorção ocorre em baixas concentrações, os valores relacionados a capacidade de 


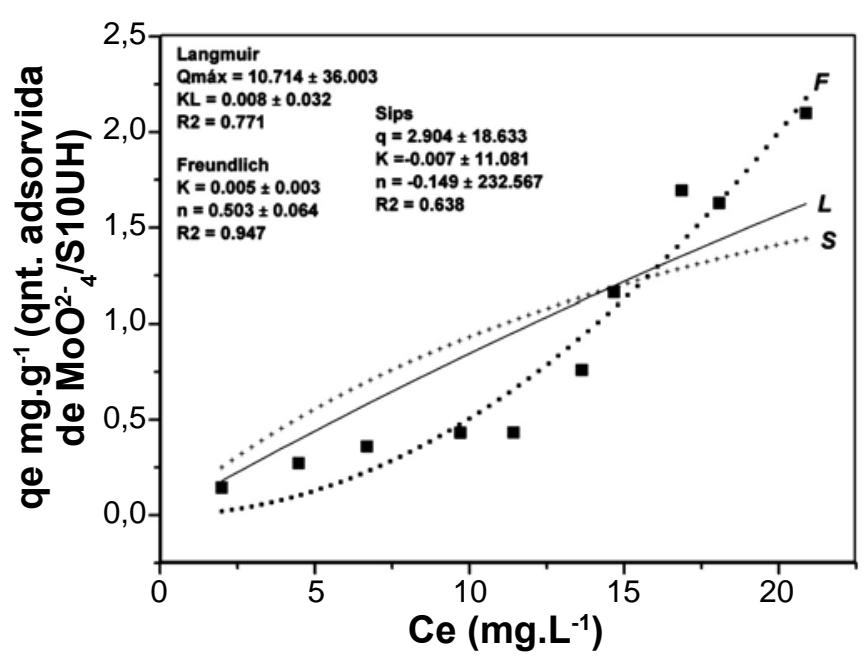

Figura 14: Amostra S10UH: modelos de isotermas de adsorção de $\mathrm{MoO}_{4}^{2-}$, à $25^{\circ} \mathrm{C}$, massa $0,05 \mathrm{~g}$ e tempo de contato: $2 \mathrm{~h}$.

[Figure 14: S10UH Sample: Models of adsorption isotherms $\left.\mathrm{MoO}_{4}^{2-}\left(25^{\circ} \mathrm{C}, 0.05 \mathrm{~g}, 2 \mathrm{~h}\right)\right]$.

adsorção $\left(\mathrm{K}_{\mathrm{L}}, \mathrm{K}_{\mathrm{f}}\right.$ e $\left.\mathrm{K}_{\mathrm{s}}\right)$ são baixos quando comparados a amostra $\mathrm{S} 10$ e S10H15, mas são favoráveis a adsorção do $\mathrm{MoO}_{4}{ }^{2-}$ e sugerem que este ânion pode estar fortemente retido na estrutura formada.

O modelo de Freundlich se ajusta adequadamente aos resultados obtidos para a amostra $\mathrm{S} 10 \mathrm{AH}$ (Fig. 15) no qual apresentou valores de correlação linear para Langmuir $\left(\mathrm{R}^{2}\right.$ $=0,83)$ Freundlich $\left(\mathrm{R}^{2}=0,91\right)$ e Sips $\left(\mathrm{R}^{2}=0,74\right)$. A alta capacidade de adsorção e a baixa energia de ligação obtida por Langmuir são semelhantes aos resultados encontrados para a amostra S10UH. A linearidade dos pontos aponta que está amostra possui a menor capacidade de adsorção, porém ela pode ocorrer ao longo da superfície formada.

O grau de desenvolvimento da adsorção das amostras S10, S10H15, S10UH e S10AH (Fig. 16) foram avaliados pelo fator de separação. Os dados apontam que todas as

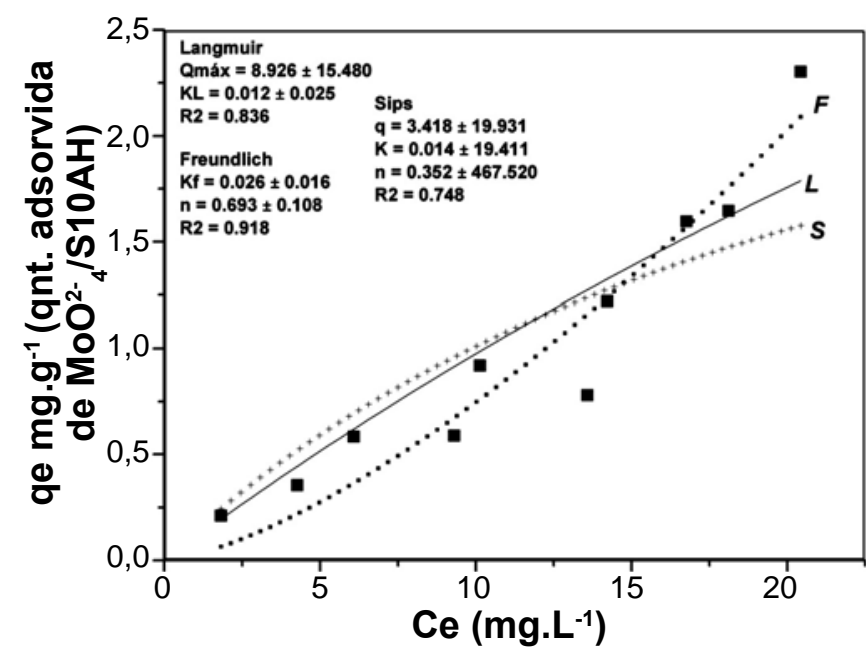

Figura 15: Amostra S10AH: modelos de isotermas de adsorção de $\mathrm{MoO}_{4}^{2-}$, à $25^{\circ} \mathrm{C}$, massa $0,05 \mathrm{~g}$ e tempo de contato: $2 \mathrm{~h}$.

[Figure 15: S10AH Sample: Models of adsorption isotherms $\mathrm{MoO}_{4}^{2-}\left(25^{\circ} \mathrm{C}, 0.05 \mathrm{~g}, 2 \mathrm{~h}\right)$.] amostras apresentam adsorção favorável $\left(0<\mathrm{R}_{\mathrm{L}}>1\right)$ e a ordem de adsorção é condizente com os resultados obtidos anteriormente [30].

Os valores da constante de distribuição Kd (Tabela IV) indicam que o $\mathrm{MoO}_{4}^{2-e ́ ~ m a i s ~ f o r t e m e n t e ~ r e t i d o ~ n a ~ f a s e ~ s o ́ l i d a ~}$ referente a amostra $\mathrm{S} 10 \mathrm{H} 15$, este resultado corrobora com as avaliações pré-estabelecidas anteriormente, nas quais a ordem de afinidade do ânion pelas amostras estudadas é: S10H5-S10-S10AH-S10UH. A seqüência de mobilidade acompanha, via de regra, a facilidade do ânion em formar complexos de alta energia, podendo explicar a formação dos polimolibdatos [31, 32].

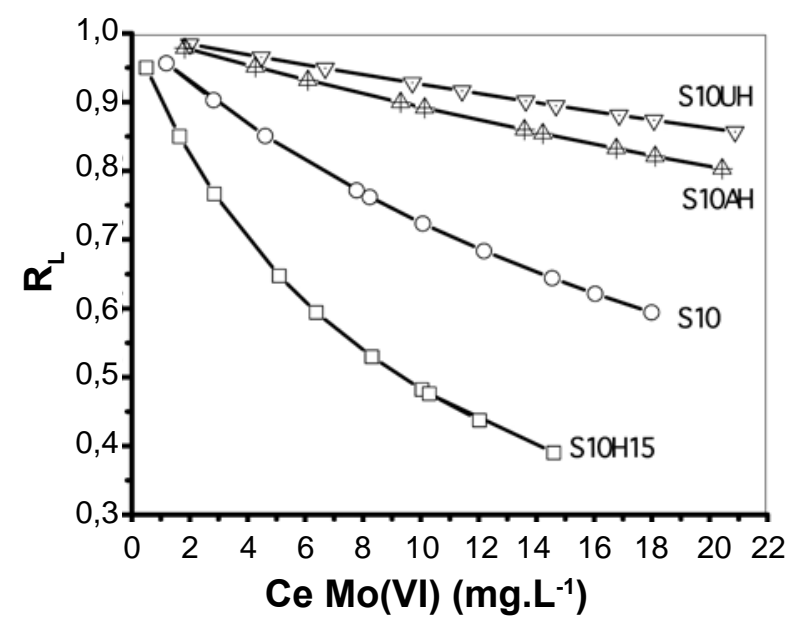

Figura 16: Parâmetro de equilíbrio $\left(\mathrm{R}_{\mathrm{L}}\right)$ da reação nas amostras S10, S10H15, S10UH e S10AH.

[Figure 16: Equilibrium parameters $\left(R_{L}\right)$ of the reaction in the samples S10, S10H15, S10UH and S10AH.].

\section{CONCLUSÕES}

Nas amostras naturais $\mathrm{S} 2$ e $\mathrm{S} 10$ caracterizadas por DRX, foram identificados como principais minerais: esmectita, ilita, caulinita, quartzo, microclíneo, albita calcita. Na amostra modificada com ácido sulfúrico ocorreu a formação de picos adicionais, referentes à fase de sílica amorfa. $\mathrm{O}$ tratamento ácido nas concentrações $(0,25 ; 0,5 ; 1$ e 1,5 mol.L-1) aliado ao tratamento térmico $\left(90^{\circ} \mathrm{C}\right)$ foram efetivos na amorfização da estrutura da esmectita.

A análise quantitativa obtida por FRX para as amostras naturais constataram teores de $\mathrm{SiO}_{2}$ e $\mathrm{Al}_{2} \mathrm{O}_{3}$ semelhantes aos encontrados na literatura para amostras que contem esmectita e caulinita.

O tratamento com uréia na amostra S10 promoveu destruição lamelar da esmectita ao longo do plano (001) com permanência dos outros minerais. A amostra organofuncionalizada (S10AH) apresentou um comportamento anômalo, pois apesar da extensa cadeia carbônica do ácido húmico, não foi observado a amorfização da estrutura da esmectita. O alargamento da distância basal (14,93 $\AA$ para 39,98 $\AA$ ) sugere que o composto orgânico possa ter formado pilares entres as lamelas da esmectita. 
Os dados obtidos por FTIR para as amostras naturais indicaram bandas características dos minerais esmectita, caulinita e quartzo. As bandas relativas às amostras modificadas foram atribuídas ao processo de delaminação e amorfização da estrutura da esmectita, assim como à possíveis reações que ocorreram na superfície e/ou bordas das lamelas.

A melhor capacidade de adsorção do ânion molibdato nas amostras modificadas ocorre em valores de $\mathrm{pH}$ inferior à 4, porém a adsorção também é favorável em pH 4 e 5.

Os dados experimentais de adsorção do ânion molibdato em solução aquosa e temperatura ambiente nas amostras S10, S10H15, S10UH e S10AH foram ajustados através do modelo não linear de Langmuir, Freundlich e Sips, Ce $V s \mathrm{q}_{\mathrm{e}}, \mathrm{pH} V s$. Qe e Kd, segundo os parâmetros obtidos a capacidade de adsorção é: S10H15, S10, S10AH e S10UH.

\section{AGRADECIMENTOS}

À CAPES pela bolsa de Mestrado concedida à primeira autora e ao CNPq pelo apoio financeiro.

\section{REFERÊNCIAS}

[1] B. Mason, C. B. Moore, "Principles of cheochemistry", J. Wiley \& Sons, $4^{\circ}$ Ed, New York (1982) p.344.

[2] C. H. Wu, S. L. Lo, C. F. Lin, C. Y. Kuo, J. Colloid 'Interface Sci. 233 (2001) 259-264.

[3] J. D. Lee, "Química inorgânica não tão concisa”, Edgard Blucher Editora LTDA, 5 Ed, S. Paulo (1999) p.381.

[4] H. Aubert, M. Pinta, "Trace elements in soils", Elsevier Ed, New York (1977) p.395.

[5] A. Vyskočil, V. Claude, J. Appl. Toxicology 19 (1999) 185-192.

[6] A. Giussani, A. D. Arogunjo, M. C. Cantone, F. Tavola, I. Veronese, Appl. Radiation Isotopes 64 (2006) 639-644.

[7] D. L. Guerra, M. R. M. C. Santos, C. Airoldi, J. Brazilian Chem. Soc. 20 (2009) 594-603.

[8] K. K. Panday, G. Prasad, V. N. Singh, J. Chem. Technology 34A (1984) 367-374.

[9] E. Kabai, N. Vajda, P. Gaca, Czechoslovak J. Phys. (2003) 181-188.

[10] M. Akçay, J. Coll. Interf. Sci. 280 (2004) 299.

[11] J. L. Velho, "Mineralogia Industrial Princípios e aplicações", 1 a Ed., Editora Lidel. Caps. 9 e 47 (2005) 89-95.

[12] P. Komadel, J. Madejova, "Acid activation of clay minerals", in F. Bergaya, B. K. G. Theng, G. Lagaly (Eds.) Handbook of Clay Science, Elsevier, Amsterdam, Holanda 1 (2006) 263-287.

[13] C. Breen, J. Madejová, P. Komadel, Appl. Clay. Sci. 10 (1995) 219-230.

[14] M. G. Rodrigues, K. R. O. Pereira, F. R. ValenzuelaDiaz, Cerâmica 52, 324 (2006) 260-263.

[15] E. Tertre, S. Castet, G. Berger, M. Loubet, E. Giffaut, Geochim. Cosmochim. Acta 70 (2006) 4579-4599.

[16] M. Schnitzer, H. Kodama, Science 153 (1966) 70-71.

[17] C. Varadachari, A. H. Mondal, D. C Nayak, K. Ghosh, Soil Biol. Biochem. 26 (1994) 1145-1149.

[18] M. Nègre, D. Vindrola, S. Spera, L. Ferraris, M. Gennari, Soil Sci. 167 (2002) 636-651.

[19] J. C. Biazzoto, H. C. Sacco, K. J. Ciuffi, A. G. Ferreira, O. A. Serra, Y. Ianamoto, J. Non-Crystalline Solids 273 (2000) 186-192.

[20] É. Makó, Z. Senkár, J. Kristóf, V. Vágvölgyi, J. Colloid Interface Sci. 294 (2006) 362-370.

[21] P. J. Phelan, S. V. Mattigod, Clay Clay Minerals 32 (1984) 45-48.

[22] J. E. Gardolinski, F. Wypych, M. Cantão, Química Nova 24 (2001) 761-767.

[23] E. Van Ranst, J. Shamshuddin, G. Baert, P. K. Dzwowa, J. Soil Sci. 49 (1998) 243-252.

[24] H. D. F. Almeida, Mineralogia, geoquímica, fertilidade e origem dos sedimentos de praia (barra em pontal) das bacias dos rios Purus e Juruá no Estado do Acre, Diss. Mestrado, UFPA, PA (2005).

[25] B. V. Raij, Avaliação da fertilidade do solo, Instituto da Potassa \& Fosfato, Piracicaba, SP (1981) 142p.

[26] E. F. Fernandes, Síntese, caracterização e aplicação do poli-hidroxication de alumínio, Diss. Mestrado, UFPA, PA (2006).

[27] F. R. V. Díaz, P. S. Santos, Química Nova 24 (2001) 345-353.

[28] F. Kooli, W. Jones, Clay Minerals 32 (1997) 633-643.

[29] C. R. Budziak-Fukamachi, A. S. Mangrich, F. Wypych, Lixiviação de uréia intercalada em caulinita, $34^{\circ}$ Reunião Anual da SBQ, Florianópolis, SC (2011).

[30] B. Tyagi, C. D. Chudasama, R. V. Jasra, Spectrochim. Acta, Part A 64 (2006) 273.

[31] B. Zhang, Y. Li, X. Pan, X. Jia, X. Wang, J. Phys. Chem. Solids 68, 243 (2007)135.

[32] B. Öztop, T. Shahwan, J. Colloid Interface Sci. (2006) 295-303.

(Rec. 13/04/2012, Ac. 08/06/2012) 